\title{
The development and design of thickened tailings discharge methods - a review
}

\author{
K.D. Seddon ATC Williams, Australia \\ M.P.A. Williams ATC Williams, Australia
}

\begin{abstract}
The development of the thickened tailings disposal technique presents a new paradigm in tailings disposal. It results in a total revision of the risk profile of a tailings storage facility (TSF), and may provide significant savings in both cost and water consumption. The method was developed by Robinsky (1975), who identified that thickening the tailings stream would create a non-segregating slurry and that a steeper overall beach angle could be achieved. The outcome is the elimination, or the substantial reduction in size of retaining embankments. This has obvious benefits.
\end{abstract}

The paper reviews the development history, and the key design and behavioural parameters that are needed for thickened tailings schemes, with an emphasis on the understanding of the fundamental geotechnical issues.

\section{Introduction}

Conventional tailings disposal in the mining industry has involved the storage of tailings in impoundments. Discharge commonly occurs from an embankment crest, and a decant pond forms at some distance down the beach. When tailings slurry at low solids concentrations is discharged onto a beach hydraulic sorting occurs. The coarser fraction deposits near the discharge point with finer material being deposited further down the beach. Slimes settle out from the slurry as it disperses into the pond. This method results in high embankments and soft, saturated, and often large slimes ponds in parts of the storage.

In contrast, the thickened tailings method eliminates slimes ponds, achieves much higher strength tailings in the storage, and provides the potential to significantly reduce the size of retaining embankments and improve water recovery. It constitutes a new paradigm for tailings storage systems, and is arguably the most significant recent development in the area.

Over time, a number of generic statements have been made regarding the perceived benefits of thickened discharge. Whilst these are usually broadly correct, there has been a tendency to accept them as dogma, i.e. believe that they are universally applicable. In all cases there are clear physical mechanisms and fundamental geotechnical principles underlying the perceived behaviour, and it is important for the future development of the method that these should be understood and properly applied.

\section{Brief history}

The concept of thickened tailings storage was developed in Canada in the early 1970s by Robinsky (1975, 1999). He identified that thickening the tailings stream sufficiently would create a non-segregating slurry i.e. hydraulic sorting would not occur on a sub-aerial beach, and that a steeper overall beach angle would be achieved. These properties permit tailings to be 'stacked', either as a low conical hill on flat ground, referred to as central thickened discharged (CTD), or as down-valley discharge (DVD).

There are now about thirty known thickened discharge schemes operating worldwide (with some that have now closed). These are summarised in Figure 1, based on data presented in Williams et al. (2008). This figure is limited to schemes that are (or have been) fully operational, and are referenced in the literature or details are known to the authors. 


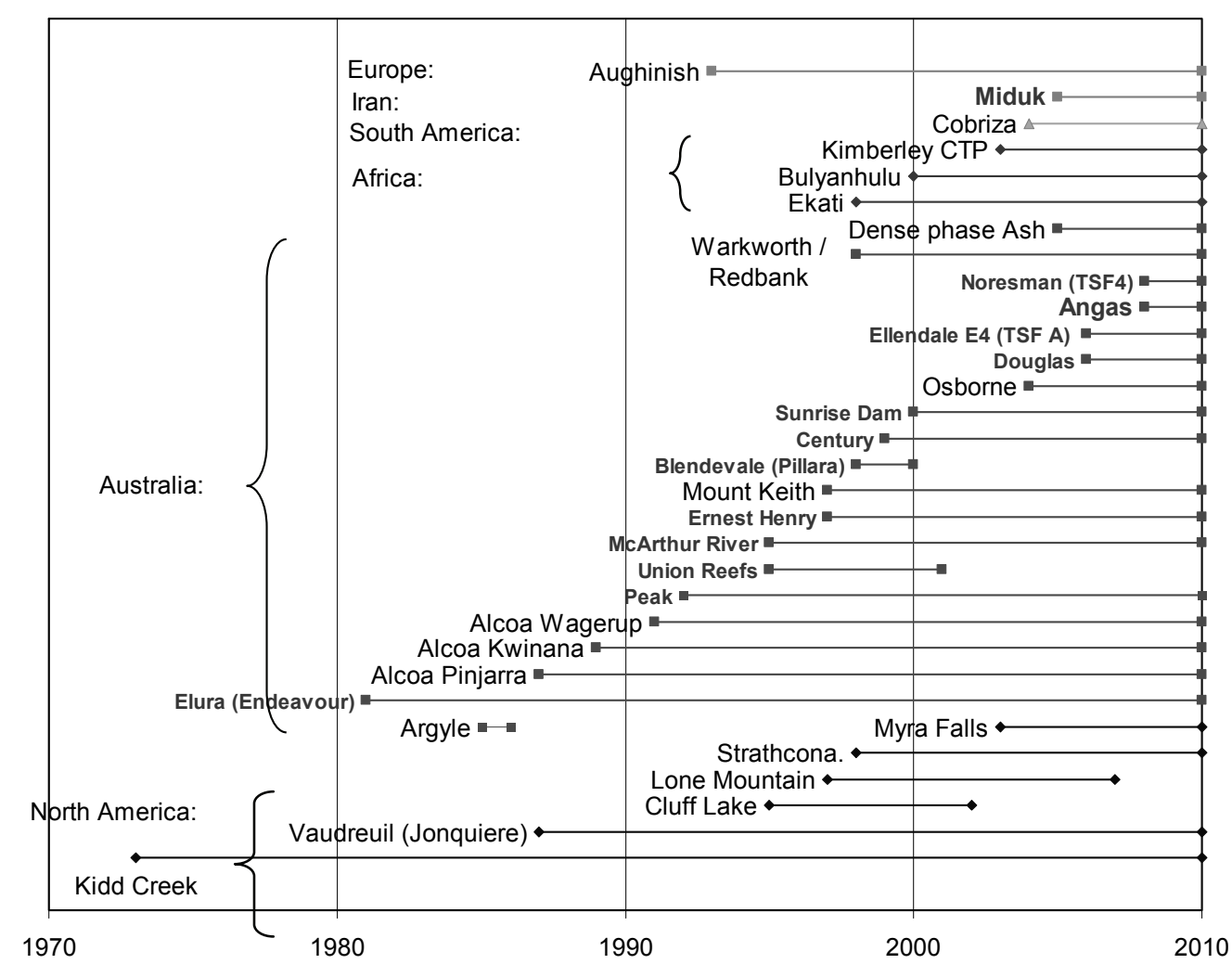

Figure 1 Time line history of thickened discharge schemes

The first application was at Kidd Creek, a base metals mine in Canada. This was followed by Elura (now Endeavour) in Australia. Further developments included a number of different strands, sometimes developed independently, possibly without full recognition of other applications. Bauxite/red mud disposal techniques evolved on three continents from the late 1980s (Cooling, 2000). A series of gold and metalliferous mines predominantly located in Australia commenced operation of thickened discharge schemes from the early 1990s. Additional metalliferous applications followed in Canada and Africa, and there are now examples in South America and Iran. In addition, the development of dense phase ash disposal has been undertaken at a number of coal-fired power stations, primarily as a water management measure. The resulting ash deposits are certainly thickened discharge, although in some cases the full potential has yet to be realised. Finally it should be noted that there are a number of examples of "inadvertent" thickened discharge schemes. These are typically cases where moderately thickened tailings are discharged down valley resulting in a low angle beach over at least part of the deposit.

There have been a number of significant changes in approach over the period (Williams et al., 2008):

- Early schemes were based on a given thickener performance, often one that had already been designed to meet other process requirements. Improvements in thickener design now introduce significant design choices.

- There is a clear move towards 'system' design that fully integrates tailings disposal into the whole mine plan, looks for the best fit and lowest cost, and seeks a match between capital and operating costs of thickening, pumping, stacking, and water consumption.

- There has been a significant increase in the emphasis on water recovery and minimising water usage.

- There has been an increased emphasis on closure and rehabilitation. 


\section{$3 \quad$ Fundamentals of thickened discharge}

\subsection{Paste or thickened tailings}

There appears to be some misconception that a step change in tailings properties and behaviour occurs between 'thickened tailings' and 'paste'. This is not so, there is a continuum in tailings slurry properties as the solids concentration is increased. All the key issues discussed in this paper apply (to a greater or lesser extent) throughout the full range of solids concentrations relevant to the concept of thickened tailings disposal.

\subsection{Key elements}

The design of a thickened tailings scheme is not simple; it requires specialist multi-disciplinary inputs (Jewell and Fourie, 2006).

The key elements of a thickened disposal scheme are:

- thickening (or slurry conditioning)

- transport

- discharge and beach formation

- settlement on the beach to an initial settled density

- subsequent increases in strength and density due to evaporative drying and consolidation.

These elements are briefly outlined in this section. Further details on some of the important geotechnical design issues are elaborated in Section 5.

\subsection{Thickening}

Thickening may be employed in a process circuit for a number of reasons other than to assist tailings disposal, including conservation of chemicals and reagents, reduction of water losses and reduction of pumping volumes and pipeline costs. Thickeners may be broadly classified (in order of increasing underflow solids concentration) as follows:

- conventional

- high rate

- high density

- paste.

Apart from the older style conventional thickeners, effective thickening technology relies extensively on correct initial flocculation. A comprehensive summary of flocculation is provided by Stocks and Parker (2006). Further details on thickening are provided by Bedell et al. (2006).

Sufficient thickening produces a non-segregating tailings slurry. This is the first important property to permit the 'stacking' of tailings, as it results in:

- a homogeneous mixture of particle sizes at all locations from the top to the bottom of the beach. Hydraulic sorting does not occur and slimes areas are avoided (Williams et al., 2008)

- a relatively steep, uniform beach slope.

It should be noted that strictly speaking there may be cases where some thickening is undertaken but nevertheless the solids particles still segregate. What should always be understood in the context of this paper is that the term 'thickened tailings' implies thickening to a slurry density where segregation will not occur.

There are also cases where the waste product stream is produced dry of a pumpable density, typically either as filter cake, or as dry solids, e.g. some power station ash. In these cases the product is not thickened at all; 
rather it is conditioned and re-pulped to the required concentration. These types of operations have the option to use very dense slurries, and at the same time retain good control of density variations.

\subsection{Transport}

Thickened tailings slurries differ significantly from water in that they are denser, exhibit strong nonNewtonian rheology, and may need to be transported above a minimum velocity to prevent settlement in the pipe. High pipeline friction losses seem to be unavoidable, and in some cases designers have opted to use positive displacement pumps. Slurry pumping and pipeline design is a specialised area that is continuing to evolve (Paterson, 2006; Williams et al., 2008).

Because of the cost issues associated with pumps and pipelines, the thickener location is a basic decision in the design of a thickened tailings scheme. The first option is for the thickener(s) to be located at the plant, in which case a high-density slurry pumping system is required to transport the tailings to the point of discharge. The alternative is for the thickener(s) to be located at or close to the discharge location, in which case it will be necessary to transport the initial unthickened tailings slurry to the thickener(s), as well transport the overflow back to the plant. An outline of the design methodology required to provide a rational decision in this matter is provided by Paterson (2005).

\subsection{Beach slope}

For a constant slurry density (or strictly, for constant slurry rheology) and flow rate, tailings will form a planar beach slope down the full length of the beach. This is the second fundamental aspect of thickened tailings disposal. In practise, fluctuations in both rheology and discharge mean that most beaches have a degree of concavity (discussed further in Section 5). The beach profile of thickened tailings is exploited to advantage by discharging the tailings onto relatively flat country until the beach runs out, or nearly runs out. The height of retaining embankments can thus be minimised.

The slurry density should have been selected to ensure that the tailings are non-segregating, resulting in uniform properties over the whole dry beach area. Whilst there may be a limited wet area at the point of water recovery, there will be no extensive slimes pond.

It is important to appreciate that whilst the actual slope angle achieved may be important with respect to storage capacity, and the stack footprint area, it is not critical to the other objectives of increased strength and density, which are obtained as a result of sub-aerial deposition (and are essentially independent of slope angle). It is only necessary to have sufficient slope to ensure that run-off of bleed and rainfall occurs from the beach area. It is, however, essential that adequate water recovery is provided to maximise exposure to evaporative drying.

The prediction of beach slope for the purpose of design is discussed in Section 5.

\subsection{Initial settlement}

The process of settlement of solids from a slurry may be considered as a sequence of:

- free (or un-hindered) settlement

- hindered settlement

- consolidation.

These processes also apply in thickening, and therefore the extent to which each of them is applicable on a tailings beach is dependent on the prior degree of thickening. Any tailings slurry that has been thickened can be expected to be above the range for un-hindered settlement. Typically underflow product from high rate thickeners will exhibit further hindered settlement, when it comes to rest on the beach, to a limiting density referred to as the initial settled density. The thicker slurries from high density and paste thickeners may already be at, or marginally denser than, the initial settled density obtained from a more dilute slurry, and no appreciable bleed water of increase in density will be observable on the beach.

The process of hindered settlement (if any) on a beach will take place over a relatively short time frame (hours to one or two days). At this point, the settled tailings still have a high water content and low strength. 
All subsequent increase in density and strength is governed by the joint processes of evaporative drying and consolidation of the tailings.

It is another misconception that enhanced thickening by itself will increase the density and strength of a deposit. This is not correct. Higher levels of thickening will certainly influence beach slope, and may result in a small increase in the initial settled density. However, this does not in itself impart significantly higher strength or density to the final tailings deposit.

\subsection{Evaporative drying and consolidation}

Increases in strength and density after tailings are deposited on a beach are due to a combination of evaporative drying and consolidation.

The degree of consolidation that can be achieved depends on the consolidation parameters of the tailings, and the placement rate. For coarse-grained tailings consolidation may keep up with the placement rate, and the deposit may be essentially normally consolidated. Whilst this gives higher strength and density at depth, it has little influence on the surface layers. For fine-grained tailings (including the slimes section of segregated storages) with a low coefficient of consolidation an under-consolidated deposit is to be expected, often through the full depth of the tailings.

The importance of evaporative drying is that it applies a pre-consolidation pressure (suction) to the tailings at shallow depths. This results in significant density and strength gains in these layers, before they are covered by subsequent deposition. This is the third, and probably least appreciated, fundamental mechanism of thickened tailings disposal.

In some cases in the alumina industry where crusting of fine grained tailings acts to reduce the effectiveness of evaporation, 'mud-farming' techniques are used to break up the crust and promote effective drying.

For both consolidation and evaporative drying, the rate of filling (rate of rise) has a critical influence on the achieved results, and must be considered in design.

\section{$4 \quad$ Risk profile of thickened discharge}

\subsection{Overview}

The mining industry looks to minimise and manage the risks associated with tailings storage facilities in a number of key areas, including safety, environmental impact, water management and recovery, closure and rehabilitation, and cost. These items are discussed below.

The risk profile that results from a thickened discharge scheme can be significantly different to a conventional tailings storage.

\subsection{Safety}

\subsubsection{Hazards}

There are two fundamental (and related) hazards likely to be associated with tailings storages, namely potential energy and low strength.

\subsubsection{Potential energy}

All above-ground storages place tailings in an elevated location relative to some position around the storage. In the event of a breach of the containment structure, this potential energy may convert to kinetic energy. This means that the run-out distances and consequences of failure need careful consideration for all storages.

The inherently lower heights, or the total absence, of embankments that may be achieved with thickened discharge are a clear distinction to the higher embankments required for conventional storages. In addition, the types of embankment employed in thickened discharge to date have generally been conventional earth and rockfill type embankments, not the more susceptible upstream or centre-line types. 


\subsubsection{Low strength}

Strength also influences run-out distances and the assessed consequences of failure. In addition, it also relates directly to bearing capacity and safe access over the tailings for activities including raising and capping, not to mention casual access by humans and animals.

The higher in situ strength achievable by the use of thickened discharge methods is another clear distinction to conventional storages.

\subsection{Environmental impact}

Ultimately it is necessary to evaluate every project (and project alternatives) on a project specific basis. This process needs to maintain a degree of perspective, and should not allow the impacts of localised/transient effects to become confused with broader area/long-term effects.

One potential difference between conventional and thickened schemes relates to seepage losses to groundwater. Conventional tailings schemes with large, more or less permanent decant ponds can be expected to generate seepage to groundwater, although the actual quantity may be dependent on the permeability of the saturated tailings. In contrast, if a thickened tailings stack is unsaturated due to evaporative drying, it can be shown that seepage losses through the stack itself can be essentially zero (Williams et al., 2008). The treatment of runoff collection and decant pond areas may require more specific attention, and lining may be required.

Dust generated off exposed surfaces during operations is often another consideration, and certainly some tailings types appear to be more prone to dusting than others. However, there are some indications that dust generation off thickened tailings stacks is less a problem than might be expected, possibly due to the tight nature of beaches formed by non-segregated tailings, combined with the regular, self-regulated rotation of deposition over the beach, so that there are always some wet areas present. More work on this aspect would be of value.

\subsection{Water management and recovery}

In some cases it is possible to configure and operate a conventional disposal scheme so that reasonable water recovery is obtained. In many cases this is not possible, and mostly it does not happen. There is no question that if minimum water use is an issue at a site, the implementation of a high level of thickening will have a significant impact.

Comparisons of water recovery should be based on the whole scheme recovery, including the thickener. It is a mistake to focus only on the recovery from the storage and omit the water already recovered from the thickener overflow from the calculation.

\subsection{Closure and rehabilitation}

It is a fact that thickened discharge schemes tend to occupy a larger surface area than conventional storages. However it would be unusual for the unit costs for closure for both types of schemes to be the same, and estimates of cost should not be made on the basis of area alone.

The ultimate objective for long-term closure of any tailings storage facility is that the tailings should stay where they have been put. They should not blow away, be washed away, or release contained contaminants at damaging concentrations into the surface or groundwater environment. Further, these objectives should be passively achievable, without the need for human management or intervention.

Thickened discharge schemes offer two significant differences to conventional storages. Firstly, conventional storages rely on embankments for containment. It is not easy to be convinced of the ultra long-term (geological time) integrity of an earth/rockfill embankment. The face slopes are often much steeper than the natural slopes of the surrounding terrain and this does not augur well for long-term erosion resistance and stability. In contrast, the final landform of a thickened discharge scheme is already moderately sloped, selfshedding and erosion resistant, and is usually in keeping with the surrounding topography. There is limited requirement to flatten off steep perimeter slopes, fill in low points or design long-term spillway/diversions from decant pond areas. 
Secondly, the issue of strength and accessibility onto conventional storages is often underestimated. In the case of thickened discharge, the tailings are likely to have sufficient strength to support earthmoving machinery immediately, without the requirement for difficult and expensive techniques often necessary to cap soft slimes pond areas. The rehabilitation of the Union Reefs tailings dam in the Northern Territory of Australia is a good example. This was a down valley thickened discharge scheme. The cover layer of 1-2 $\mathrm{m}$ of waste rock was hauled and placed directly onto the tailings surface using $90 \mathrm{t}$ mine trucks immediately following cessation of operations.

\subsection{Cost}

Cost is clearly another factor that must be determined on a project specific basis and cannot be generalised. However, it is suggested that thickened discharge schemes should always be considered in the project evaluation phase. One study (Williams and Seddon, 2004) showed whole of mine life cost for a conventional paddock system in the range $50-150 \%$ greater than a thickened tailings scheme.

\subsection{Risk profile}

On the basis of the preceding discussion, a notional risk profile for a conventional tailings storage is compared to a profile for a thickened tailings storage in Table 1. From the point of an overall perspective it should be apparent that thickened tailings schemes provide some inherent and clear differences in the risk associated with conventional tailings storages.

A rational selection of storage options should consider both risk and cost components.

Table 1 Comparison of possible risk profiles

\begin{tabular}{|c|c|c|c|}
\hline \multicolumn{4}{|c|}{ RISK (Probability $\times$ Consequence) } \\
\hline Phase & Component & Conventional & Thickened \\
\hline \multirow[t]{5}{*}{ Operational: } & Foundation failure & $\mathrm{L}$ & VL \\
\hline & Embankment failure & $\mathrm{L}-\mathrm{M}$ & VL \\
\hline & Failure-overtopping & $\mathrm{L}-\mathrm{M}$ & $\mathrm{L}$ \\
\hline & Contamination - surface water & $\mathrm{L}$ & $\mathrm{L}$ \\
\hline & Contamination - groundwater & $\mathrm{L}$ & $\mathrm{VL}-\mathrm{L}$ \\
\hline \multirow[t]{2}{*}{ Closure: } & Poor trafficability and access & $\mathrm{H}$ & VL \\
\hline & Erodability of final landforms & $\mathrm{H}$ & VL \\
\hline
\end{tabular}

Scale: Very Low - VL, Low L - Medium M - High H - Very High VH.

\section{$5 \quad$ Some design issues}

\subsection{Thickening and rheology modification}

\subsubsection{Aspects of thickener design}

The amount and type of flocculent added during the thickening process will influence the resulting slurry rheology. This must be taken into account in sample acquisition and preparation prior to rheological testing.

In general, the degree of thickening that can be achieved in any given thickener is limited by the rheology (static yield strength) of the underflow. Thickeners are designed for this limit on the basis of the expected rheological and setting characteristics of a particular tailings type. All thickeners have an operating range somewhere below the design maximum. Designers of tailings schemes should resist the temptation to assume that thickeners will routinely perform to the design maximum. 
It is a common site practice to equate underflow solids concentration with the rheological parameters of the slurry, i.e. slurry density is used as the controlling measure for thickener performance. There are limits to the validity of this assumption. It is important to realise that thickeners are only designed to produce a given underflow solids concentration to the extent that the rheology and settling characteristics of the feed slurry comply with the original design assumptions. In short, if the rheology of the tailings feed changes, there are likely to be unexpected changes in underflow solids concentration, and in the resulting beach slope. This should be expected at any site where different types of ore are to be processed. Designers should consider the adoption of rheological based parameters for thickeners control.

It also follows that it is next to meaningless to compare the performance of thickeners (and thickened discharge schemes) at different sites on the basis of solids concentration. Very broad comparisons may be possible between sites where the tailings characteristics are known or expected to be relatively similar and uniform (e.g. some porphyritic copper deposits), but even then minor variations can have significant effects. The greater the difference between sites, the less valid is any comparison on the basis of concentration.

\subsubsection{Rheology modification (pipe head flocculation)}

The influence of flocculation has given rise to the recent development of 'point of discharge' or 'pipe-head' flocculation/slurry modification, which may be employed as an alternative to thickening. In this practice, relatively high doses of flocculent/modifier are added to the slurry pipe close to the point of discharge. Final mixing occurs in the last section of pipe, and a typically 'over-flocculated' discharge occurs. It has been found that the modified rheology results in beach slopes comparable to those achieved by thickening. Furthermore, it appears that the flocculated structure has enough strength to remain open long enough for an appreciable degree of drainage to occur, with the result that in some cases increases in initial settled density may be obtained.

Because of the high operating costs of this method it will not be universally applicable. Possible applications are likely to be on sites where: a) enhanced beach slopes are required without the capital cost of a thickening system; b) short-term improvements in water recovery are required; and c) there is a need to improve shear strength of surface layers as an aid to capping and rehabilitation.

\subsection{Density testing}

Tests for settled density are typically carried out in columns or trays. Containers with relatively high width/depth ratios are preferred to avoid the influence of side friction. It may also be the case that measured settled density is dependent on the mass (thickness) of the sample tested. This is because in cases where consolidation is relatively rapid the settled density will include some degree of consolidation. The results are therefore susceptible to the thickness of the tested sample.

Tests on a range of sample thicknesses are recommended to quantify this effect.

\subsection{Beach slope prediction and variability}

\subsubsection{Beach slope prediction}

Beach slope is one of the most important parameters needed for the design of a surface disposal stack. A number of different approaches have been developed to address this problem including statistical correlations, pilot scale slump/flume tests and theories to correct or extend these, and channel flow methods based on a geomorphologic model of delta formation, all as summarised in Williams (2001) and Williams et al. (2008).

The geomorphologic model is based on visual observations of thickened tailings beach formation, which universally indicate that tailings flows across the beach, not in uniform ever-expanding sheets, but in selfformed channels, of definite and limited width. Only at the end of the channel is flow observed to spread out into localised sheets and come to a halt. Deposition only occurs in the terminal fans. No deposition occurs in the channels. The channels are simply the mechanism of conveying tailings to achieve a final minimum potential energy configuration. Over a period of time, the channels randomly redirect themselves (through the full $360^{\circ}$ range in the case of a CTD stack) to achieve an even build-up of tailings over the whole beach. 
By observation, the slopes of the deposition fans are steeper than the channels; the fans are localised features. The channel slope dictates the overall stack slope. The key to recent progress in the development of predictive models has been the detailed observation and measurement of channel flow in a large flowthrough flume (Pirouz and Williams, 2007; Fitton, 2007; Fitton et al., 2007).

Both observation and channel theory indicate that provided the flow regime is maintained, slope $(\boldsymbol{\beta})$ is dependent on a rheological strength parameter $(\Lambda)$, based either on the Bingham or Hershel-Bulkley models, and flow rate $(\mathrm{q})$ as follows:

$$
\boldsymbol{\beta}=\mathrm{f}\left\{\Lambda^{\mathrm{n}} / \mathrm{q}^{\mathrm{m}}\right\},
$$

where $\mathrm{n}, \mathrm{m}$ may be determined by theory or empirically.

An important corollary of the geomorphologic model is that small-scale stack tests or flume deposition tests need to be treated with extreme caution as prediction tools.

\subsubsection{Beach slope variability}

Beach slope design is based on the proposition that for a constant slurry rheology and flow rate, tailings will form a uniform, planar beach slope. In practice slurry rheology and flow rate are never truly uniform due to variability in thickener performance. Thickened tailings will therefore deposit to form a concave beach profile (Fitton et al., 2007). This should not be confused with the much more pronounced concavity that results from segregating tailings deposition.

\subsection{Evaporative drying and density}

The results of a typical shrinkage limit test are shown in Figure 2. This indicates that the sample commenced from an initial settled density around $0.75 \mathrm{t} / \mathrm{m}^{3}(\mathrm{w}=98 \%)$ and dried back to a final (shrinkage limit density) around $1.60 \mathrm{t} / \mathrm{m}^{3}$. The theoretical curve for $100 \%$ saturation is also shown, and indicates that the tailings remain saturated until very close to the shrinkage limit density. The matrix suction at the shrinkage limit has been inferred to be around $150 \mathrm{kPa}$.

A preliminary evaluation of whether tailings will dry to the shrinkage limit can be achieved by comparing the evaporation rate (in units of $\mathrm{mm} /$ day) with the water loading rate $(W L R)$ of a stack:

$$
W L R=\frac{1000 R\left(w_{i s d}-w_{\text {sld }}\right)}{A}
$$

where

$\begin{array}{lll}W L R & = & \text { water loading rate, } \mathrm{mm} / \mathrm{day} . \\ w_{\text {isd }} & = & \text { the moisture content at the initial settled density, } \mathrm{w} / \mathrm{w} . \\ w_{\text {sld }} & = & \text { the moisture content at the shrinkage limit density, } \mathrm{w} / \mathrm{w} . \\ R & = & \text { tailings production rate, } \mathrm{t} / \text { day. } \\ A & = & \text { stack area, } \mathrm{m}^{2} .\end{array}$

If the daily evaporation rate exceeds the $W L R$ then the deposit will be unsaturated. Of course for most sites, the magnitude of daily evaporation will vary significantly on a seasonal basis, and this needs to be included in the design considerations (Seddon and Dillon, 2009). 


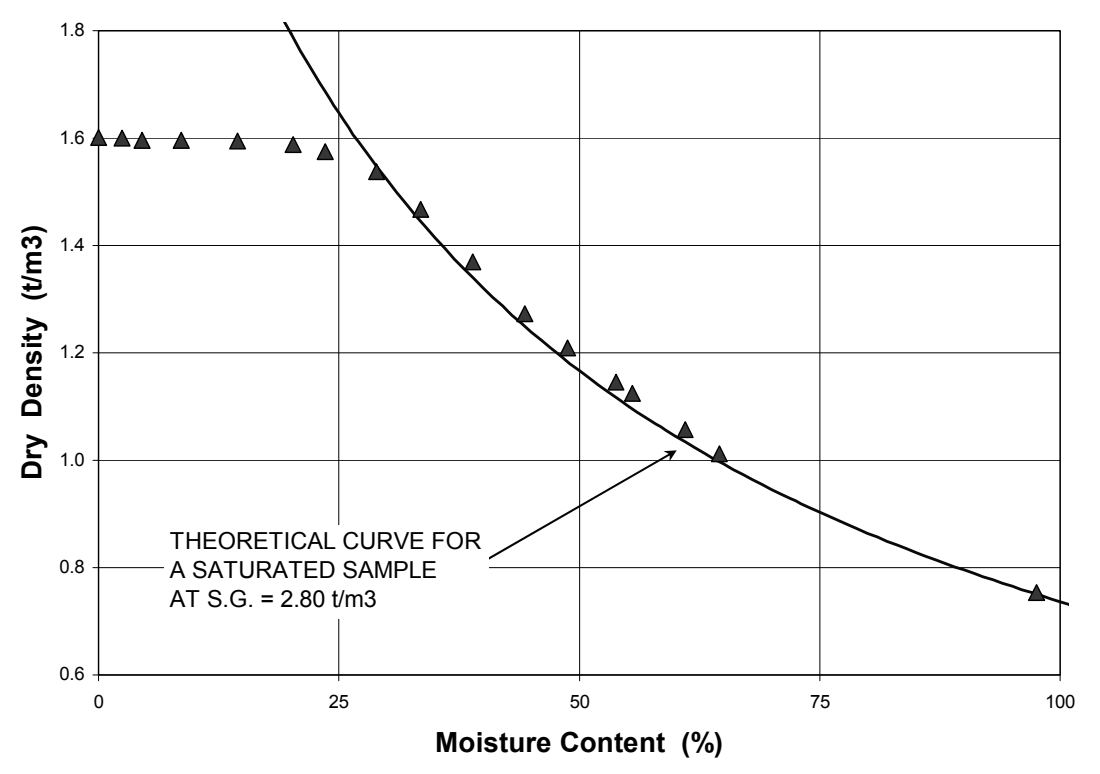

Figure 2 Example of a shrinkage limit density test result

\subsection{Undrained shear strength}

The undrained shear strength of tailings in a beach is a function of the moisture content and density of the tailings, and can be rationally analysed. The effects of surface area and evaporative drying can be combined to predict the final moisture content, density and shear strength achieved on a beach (Seddon and Dillon, 2009).

The influence of climate and tailings type can be important. Under critical combinations of climate, tailings and placement rate, very low strength layers may remain in the tailings at depth. In the first instance, a static type failure may result, i.e. a failure without any triggering mechanism such as an earthquake.

\subsection{Liquefaction stability}

The liquefaction stability of stacked tailings deposits is a serious concern, particularly in countries with a higher level of seismic risk. It was reviewed in some detail by Seddon (2007).

A number of conditions must exist before large scale flow-slide failure of a tailings stack will occur during or immediately following an earthquake (Williams et al., 2008):

1. The tailings must be saturated (without full saturation, or very close to it, shaking will not generate the necessary excess pore pressures needed to create the liquefied condition).

2. The tailings must exhibit a brittle/contractive stress response to shearing.

3. A sufficiently large earthquake must occur (large accelerations for an appreciable number of shaking cycles) to generate the strains necessary to reduce the strength to the steady state undrained condition.

4. The reduced shear strength in this condition must be less than the destabilising down-slope stresses, in which case a liquefaction flow slide will occur. At flatter slopes (lower stresses) it is possible for liquefaction to occur but the slope may remain stable.

Point 1 is significant in the context of the saturation modelling and field measurements discussed in Section 5.4. Depending on climate, it is possible for a well designed stack to be unsaturated, in which case the liquefaction issue does not arise.

Point 2: In the normally consolidated condition many or most tailings materials are contractive. However, it seems that higher fines content suppresses the characteristic brittle response obtained in sands and silty sands, to the extent that some tailings may be inherently resistant to liquefaction. Nevertheless, there is at least one case where clayey tailings are held to have liquefied under seismic conditions (Isihara et al., 1980). 
If it can be guaranteed that the top part of a deposit is over-consolidated due to the suction effects of evaporative drying, the strength for over-consolidated tailings may be substituted for normally consolidated strength.

Point 3: The analysis for this case is complex, and in many cases may be omitted if the tailings can be shown to be stable under liquefied conditions (Point 4). Poulos et al. (1985) give a case history, which relied on this type of analysis.

Point 4: In the context of flow stability, the use of the word "liquefaction" is unfortunate and potentially misleading. To the non-technical person it implies that tailings will behave like water, and will therefore flow like water. This is not the case. Liquefied tailings will still possess a positive, although low, shear strength, both during and after the earthquake. Whether or not a flow failure will occur will depend on the slope of the beach. Seddon (2007) showed that surficial sliding was unlikely to occur at slopes flatter than $5 \%$, and that deep seated failures would require slope angles steeper than $5 \%$.

In summary, the assumption of liquefaction following a seismic event, in turn leading to disastrous flowslides, is not an automatic consequence of thickened tailings stacks.

\section{Conclusions}

The thickened tailings method results in a different risk profile compared to more conventional storage options. Significant differences include lower containing embankments, better strength in the deposited tailings, significantly improved water recovery, and reduced potential for seepage to groundwater.

Good design practice dictates that tailings storage schemes should be selected on the basis of minimising both cost and risk. Thickened discharge schemes should always be considered in the project evaluation phase of any new project.

There are now at least thirty examples of thickened discharge world-wide, and in any context the method should be considered 'proven'.

Further advances can be expected in most of the key areas, including thickener and pump design and beach slope prediction. More detailed studies on some environmental aspects (such as dust) would also be valuable.

\section{References}

Bedell, D., Slottee, S., Baczek, F., Schoenbrunn, F., Phillips, M., Wallace, J. and Triglavcanin, R. (2006) Thickening and Filtration, in Paste and Thickened Tailings - A Guide, 2nd edition, R.J. Jewell and A.B. Fourie (eds), Australian Centre for Geomechanics, Perth, Chapter 7, pp. 95-122.

Cooling, D. (2000) Alcoa - "Stacked Tailings", in An International Seminar on the Production and Disposal of Thickened/Paste Tailings for Mine Backfill or on the Surface (Paste Technology 2000), 13-14 April 2000, Perth, Australia, Australian Centre for Geomechanics, Perth, Section 18, 29 p.

Fitton, T.G. (2007) Tailings beach slope prediction, PhD thesis, RMIT University, Melbourne, Australia.

Fitton, T.G., Williams, M.P.A., Seddon, K.D., Bhattacharya, S.N. and Chryss, A.G. (2007) Simulation of thickened tailings stacks, in Proceedings Tenth International Seminar on Paste and Thickened Tailings (Paste07), A.B. Fourie and R. Jewell (eds), 13-15 March 2007, Perth, Australia, Australian Centre for Geomechanics, Perth, pp. 305-313.

Ishihara, K., Troncoso, J.H., Kawase, Y. and Takahashi, Y. (1980) Cyclic Strength Characteristics of Tailings Materials, Soils and Foundations, Vol. 20, No. 4.

Jewell, R.J. and Fourie, A.B. (eds) (2006) Paste and Thickened Tailings - A Guide, 2nd edition, Australian Centre for Geomechanics, Perth.

Paterson, A. (2006) High Concentration Hydraulic Transport Systems, in Paste and Thickened Tailings - A Guide, 2nd edition, R.J. Jewell and A.B. Fourie (eds), Australian Centre for Geomechanics, Perth, Chapter 8, pp. 95-122.

Paterson, A.J.C. (2005) Determining the optimum location of a high rate thickener for a thickened tailings system, in Proceedings Eighth International Seminar on Paste and Thickened Tailings (Paste05), R. Jewell and S. Barrera (eds), 20-22 April 2005, Santiago, Chile, RIL Editors, Santiago, pp. 177-184.

Pirouz, B. and Williams, M.P.A. (2007) Prediction of Non-segregating Thickened Tailings Beach Slope, in Proceedings Tenth International Seminar on Paste and Thickened Tailings (Paste07), A.B. Fourie and R. Jewell (eds), 13-15 March 2007, Perth, Australia, Australian Centre for Geomechanics, Perth, pp. 315-327.

Poulos, S.J., Robinsky, E.I. and Keller, T.O. (1985) Liquefaction Resistance of Thickened Tailings, ASCE Journal Geotechnical Engineering, Vol. 111/12. 
Robinsky, E.I. (1975) Thickened discharge — a new approach to tailings disposal, CIM Bulletin, Vol. 68, No. 764, pp. 47-53.

Robinsky, E.I. (1999) Thickened Tailings Disposal in the Mining Industry, E.I Robinsky Associates Limited, Toronto, Canada.

Seddon, K.D. (2007) Post Liquefaction Stability of Thickened Tailings Beaches, in Proceedings Tenth International Seminar on Paste and Thickened Tailings (Paste07), A.B. Fourie and R. Jewell (eds), 13-15 March 2007, Perth, Australia, Australian Centre for Geomechanics, Perth, pp. 395-406.

Seddon, K.D. and Dillon, M.J. (2009) The Effect of Evaporation on Strength and the Stability of Thickened Tailings Beach Slopes, in Proceedings Twelfth International Seminar on Paste and Thickened Tailings (Paste09), R. Jewell, A.B. Fourie, S. Barrera, J. Wiertz (eds), 21-24 April 2009, Viña Del Mar, Chile, Gecamin Limited, Santiago, pp. 261-269.

Stocks, P. and Parker, K. (2006) Reagents, in Paste and Thickened Tailings - A Guide, 2nd edition, R.J. Jewell and A.B. Fourie (eds), Australian Centre for Geomechanics, Perth, Chapter 6, pp. 79-90.

Williams, M.P.A. (2001) Tailings Beach Slope Forecasting - A Review, Proceedings of the High Density and Paste Tailings 2001 Seminar, University of the Witwatersrand, South Africa.

Williams, M.P.A. and Seddon, K.D. (2004) Delivering the Benefits (2): Case History of Century Zinc and Sunrise Dam Gold Mine, in Proceedings International Seminar on Paste and Thickened Tailings (Paste 2004), Cape Town, South Africa, March-April, 2004.

Williams, M.P.A., Seddon, K.D. and Fitton, T.G. (2008) Surface Disposal of Paste and Thickened Tailings: A Brief History and Current Confronting Issues, in Proceedings Eleventh International Seminar on Paste and Thickened Tailings (Paste08), A.B. Fourie, R. Jewell, P. Slatter and A. Paterson (eds), 5-9 May 2008, Kasane, Botswana, Australian Centre for Geomechanics, Perth, pp. 143-164. 